NIST Special Publication 2000-02

\title{
Conformity Assessment Considerations for Federal Agencies
}

Lisa Carnahan

Amy Phelps

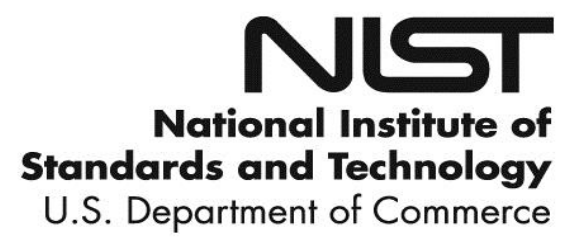




\section{NIST Special Publication 2000-02}

\section{Conformity Assessment Considerations for Federal Agencies}

Lisa Carnahan

Amy Phelps

Standards Coordination Office

This publication is available free of charge from:

https://doi.org/10.6028/NIST.SP.2000-02

September 2018

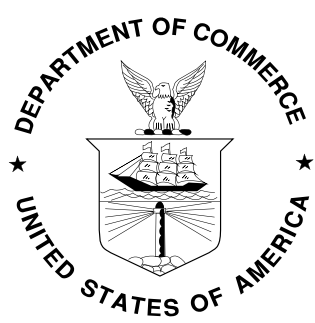

U.S. Department of Commerce Wilbur L. Ross, Jr., Secretary

National Institute of Standards and Technology Walter Copan, NIST Director and Under Secretary of Commerce for Standards and Technology 
Certain commercial entities, equipment, or materials may be identified in this document in order to describe an experimental procedure or concept adequately. Such identification is not intended to imply recommendation or endorsement by the National Institute of Standards and Technology, nor is it intended to imply that the entities, materials, or equipment are necessarily the best available for the purpose.

Publications in the SP 2000 subseries provide detailed descriptions of important activities and features related to the use and harmonization of standards and conformity assessment in the United States and globally. The publications include reports, guidelines, and other information resources on key concepts, activities, features, and other specific topics regarding coordination of standards and use of conformity assessment impacting both international and U.S. trade.

\section{National Institute of Standards and Technology Special Publication 2000-02 \\ Natl. Inst. Stand. Technol. Spec. Publ. 2000-02, 33 pages (September 2018) \\ CODEN: NSPUE2}

This publication is available free of charge from: https://doi.org/10.6028/NIST.SP.2000-02 


\title{
Foreword
}

The NIST Standards Coordination Office (SCO) is responsible for implementing the documentary standards and conformity assessment coordination provisions of the National Technology Transfer and Advancement Act. The conformity assessment provisions are to coordinate Federal, State, and local technical standards activities and conformity assessment activities with private sector technical standards activities and conformity assessment activities, with the goal of eliminating unnecessary duplication and complexity in the development and promulgation of conformity assessment requirements and measures. SCO provides guidance, training, information, and assistance to government so that industry, government agencies, conformity assessment bodies, standards bodies, and other stakeholders can successfully work together on essential standardization and conformity assessment activities.

The Standards Coordination Office periodically publishes information related to standards and conformity assessment as a service. The interested reader may wish to take advantage of other publications and services provided by the Standards Coordination Office. See https://www.standards.gov for more information.

\begin{abstract}
This document provides those not fully familiar with the field of conformity assessment an introduction to the complexities in developing, operating, using or relying on conformity assessment programs to meet Federal legislation or Federal government agency missions, regulations, or procurement requirements. We hope this document is informative and serves to enhance understanding of the purpose and nature of various aspects of conformity assessment and their application and use in Federal agency conformity assessment programs.
\end{abstract}

\section{Key words}

Attestation; conformity; inspection; standard; testing; surveillance; oversight. 


\section{Acknowledgements}

The authors acknowledge and thank the following for their insight and perspectives on federal agency conformity assessment programs: Roger Butturini, U.S. Coast Guard; Michael Cooper, NIST; Matthew Goodrich, General Services Administration; Scott Heh, Consumer Product Safety Commission; Kevin Robinson, Occupational Safety and Health Administration; and members of the Interagency Committee of Standards Policy (ICSP) and the ICSP Conformity Assessment Working Group. We also acknowledge and thank the members of the following organizations for their perspectives on business, industry and conformity assessment: the Advanced Medical Technology Association, the American Council for Electrical Safety, the American Council of Independent Laboratories, the American National Standards Institute (ANSI) Conformity Assessment Policy Committee, the ANSI Company Member Forum, the International Federation of Inspection Agencies, the Information Technology Industry Council, and the U.S. National Committee of the International Electrotechnical Commission Conformity Assessment Policy Coordination Committee. We would also like to thank Jasmeet Seehra, the Office of Management and Budget, Jennifer Stradtman, Office of the U.S. Trade Representative, and Eileen Hill and Renee Hancher, International Trade Administration for expertise and guidance on Federal policy, regulatory requirements and international obligations for Federal agencies. Finally, we would like to thank the participants of NIST's February 2017 Conformity Assessment Workshop and our colleagues from NIST's Standards Coordination Office for providing valuable input to the approach taken in this publication. 


\section{Table of Contents}

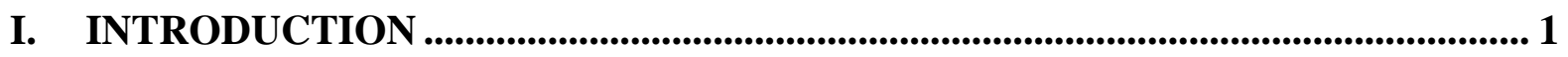

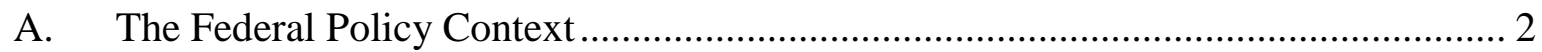

B. Foundational Considerations for Federal Conformity Assessment Programs ............ 3

II. ELEMENTS OF A CONFORMITY ASSESSMENT PROGRAM............................. 5

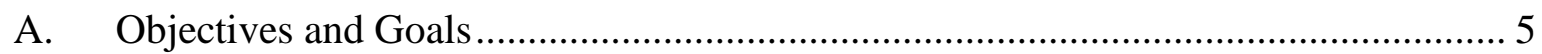

1. Understand conformity assessment concepts ……………………………………..... 5

2. Understand Federal law, policies, and international obligations .................................... 5

3. Understand the objectives of the underlying law, regulation, procurement or mission.... 6

4. Understand how conformity assessment program goals support agency objectives ........ 7

5. Know the market and current conformity assessment programs ………………………. 7

B. Conformity Assessment Scheme and Oversight ................................................... 8

1. Determine the confidence point ......................................................................... 8

2. Define the conformity assessment scheme …………………………………….... 10

3. Develop requirements for conformity assessment bodies ............................................ 12

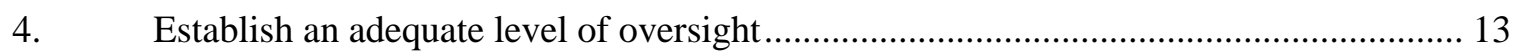

C. Requirements for the Object of Conformity..................................................... 14

1. Determine requirements to be met by the object of conformity …………………….... 14

2. Leverage existing standards ........................................................................... 15

3. Define the method for determining conformity ……………................................... 16

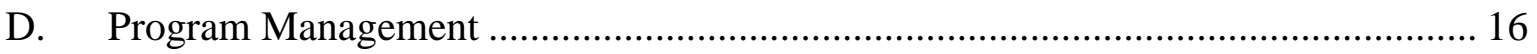

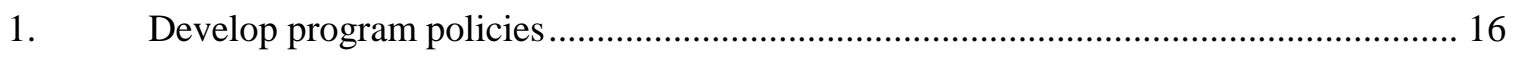

2. Address communications, outreach and engagement .................................................. 17

3. Address updates, improvement and evolution ………………………...................... 17

4. Identify resource needs .......................................................................................... 18

III. CONSIDERATIONS IN BRIEF ..................................................................................... 20

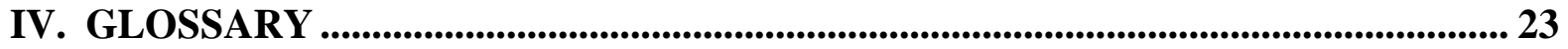

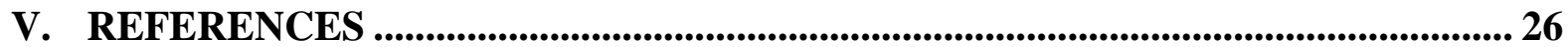

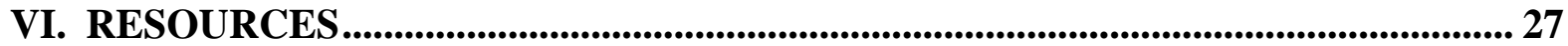

\section{List of Figures}

Figure 1 - A conceptual framework for a conformity assessment program ................................. 1

Figure 2 - Conformity assessment flexibility to meet confidence needs ......................................... 9

\section{List of Tables}

Table 1 - A synopsis of the suggestions and considerations. 


\section{INTRODUCTION}

This document supports Federal agencies in using conformity assessment in an efficient and cost-effective manner for both the agency and its stakeholders. Conformity assessment is used in Federal programs to provide confidence that requirements in legislation, regulation, policy, and procurement are met. This document is directed at agency program personnel, agency subject matter experts, regulators, agency counsel, managers and administrators. Other stakeholders in conformity assessment programs may find this document helpful. These stakeholders may include producers, suppliers, purchasers, consumers, trade associations, industry associations, professional associations, non-governmental organizations, standards development organizations, and conformity assessment bodies. ${ }^{1}$

A general understanding of conformity assessment (see Figure 1), conformity assessment roles and conformity assessment activities is helpful to more fully comprehend topics covered in this document. This document assumes the reader's general understanding of these subjects. Readers are encouraged to use NIST Special Publication (SP) 2000-01 ABC's of Conformity Assessment and the Resources Section for an overview of the basic concepts and terms of conformity assessment.

\begin{tabular}{|c|c|c|c|}
\hline $\begin{array}{c}\text { REQUIREMENT } \\
\text { How should it } \\
\text { perform? }\end{array}$ & $\begin{array}{c}\text { DETERMINATION } \\
\text { How do we know it } \\
\text { performs? }\end{array}$ & $\begin{array}{c}\text { ATTESTATION } \\
\text { Who says its } \\
\text { performance has } \\
\text { been demonstrated? }\end{array}$ & $\begin{array}{c}\text { SURVEILLANCE } \\
\text { What about } \\
\text { assurances next } \\
\text { week? }\end{array}$ \\
\hline
\end{tabular}

Figure 1 - A conceptual framework for a conformity assessment program

There are a number of factors that affect a Federal agency conformity assessment program, including the agency's mission; regulations underpinning the need for the conformity assessment program; the dynamics of specific markets and sectors in the U.S. and internationally; and the current state of conformity assessment programs within the area of interest. This document presents a discussion of these related factors. Along with this document, readers are encouraged to refer to the online resources including examples of Federal agency conformity assessment programs representing broad variations in the use of conformity assessment and includes links to programmatic, oversight, and communication approaches. Online resources are found at https://www.nist.gov/standardsgov/conformity-assessment-resources-federal-agencies.

This document uses conformity assessment terms based on ISO/IEC conformity assessment definitions and standards. ${ }^{2}$ (See the Glossary Section and the Resources Section.) Agencies are

\footnotetext{
${ }^{1}$ In this document the term conformity assessment bodies includes testing laboratories, inspections bodies, certification bodies, and accreditation bodies.

${ }^{2}$ ISO (International Organization for Standardization) and IEC (International Electrotechnical Commission) are international standards organizations and work together on international standards related to conformity assessment topics.
} 
encouraged to use terms consistent with the ISO/IEC standards. Note that some agencies use differing terms to remain consistent with established usage by their stakeholder communities, or with authorizing legislation. Whatever terms are used, clarity with respect to definition, semantics and application is necessary.

\section{A. The Federal Policy Context}

This document provides information for agencies to use as they deem appropriate to support implementation of Federal legislation, policy and guidance. This document is not prescriptive in its suggestions.

The Office of Management and Budget (OMB) Revised Circular A-119 (2016) Federal Participation in the Development and Use of Voluntary Consensus Standards and in Conformity Assessment Activities ${ }^{3}$ (the Circular) establishes policies on Federal use and development of voluntary consensus standards and conformity assessment in regulatory, procurement, and program activities. The Circular provides factors for agencies to consider when assessing the effectiveness of conformity assessment options and determining the type(s) of conformity assessment activities to employ. (p. 4) These factors are incorporated into Section II of this document.

Agencies should be aware that conformity assessment activities and systems can be used in different ways to support their missions. The Circular advises agencies to work closely with OMB and NIST ${ }^{4}$ to identify their conformity assessment needs in such areas as regulatory compliance and enforcement, procurement, and other programmatic contexts and to assess whether the use of private sector conformity assessment mechanisms in whole or in part would be beneficial and should be considered.

The Circular refers to NIST guidance in 15 CFR $\S 287$, Guidance on Federal Conformity Assessment Activities ${ }^{5}$ which furthers agency implementation of the Circular and provides recommendations to agencies in evaluating the efficacy and efficiency of their conformity assessment activities. To reduce unnecessary burden and make more productive use of Federal resources, the NIST guidance suggests that each agency coordinate its conformity assessment activities with those of other appropriate government agencies and with those of the private sector. The NIST guidance does not preempt the agency authority and responsibility to make regulatory or procurement decisions authorized by statute or required to meet programmatic objectives and requirements.

\footnotetext{
${ }^{3}$ OMB Revised Circular A-119 Federal Participation in the Development and Use of Voluntary Consensus Standards and in Conformity Assessment Activities is available at https://www.whitehouse.gov/sites/whitehouse.gov/files/omb/circulars/A119/revised_circular_a119 as_of_1_22.pdf.

4 The National Technology Transfer and Advancement Act of 1995 (Public Law 104-113, 1996) (NTTAA) authorizes NIST to coordinate conformity assessment activities. The NTTAA states that NIST coordinates "Federal, State, and local technical standards activities and conformity assessment activities, with private sector technical standards activities and conformity assessment activities, with the goal of eliminating unnecessary duplication and complexity in the development and promulgation of conformity assessment requirements and measures."

5 See https://www.gpo.gov/fdsys/pkg/CFR-2016-title15-vol1/pdf/CFR-2016-title15-vol1-part287.pdf.
} 
Federal agencies have statutory and international obligations concerning conformity assessment. The obligations state that "[e]ach Federal agency shall, with respect to any conformity assessment procedure used by it, permit access for obtaining an assessment of conformity and the mark of the system, if any, to foreign suppliers of a product on the same basis as access is permitted to suppliers of like products ..." (OMB A-119, p. 31). The World Trade Organization Technical Barriers to Trade Agreement (the TBT Agreement), of which the United States is a signatory, requires the United States to ensure that it does not [use] conformity assessment procedures [that] create unnecessary obstacles to international trade. ${ }^{6}$ Articles 5 through 9 of the TBT Agreement set out detailed obligations on conformity assessment procedures falling within the scope of the TBT Agreement. Agencies should be familiar with these obligations with attention given to Articles 5.1 and 5.2. and should contact the Office of the United States Trade Representative (USTR) for more information and guidance. In addition, OMB A-119 points out that "U.S. free trade agreements" may also have obligations with respect to recognition of trading partners' conformity assessment procedures. Agencies should consult with USTR regarding compliance with these obligations. Agencies should consult with the Department of State in the case of other international obligations or to consider what other relevant international agreements may apply." (p. 32)

This document promotes Federal agency conformity assessment programs that

- meet, as appropriate, the policies in the Circular, NIST guidance, and international obligations; and

- make appropriate use of the conformity assessment principles and practices encompassed in conformity assessment standards (see the Resources Section).

\section{B. Foundational Considerations for Federal Conformity Assessment Programs}

These general considerations are effective when designing, developing, and operating a conformity assessment program.

1. Engage Stakeholders: Engage stakeholder groups during each phase of program design, development, and operations. Stakeholders bring expertise, knowledge, and perspective that help inform agency decisions. To the extent feasible, a collaborative approach with the private sector (and other agencies with like requirements) often results in agency decisions and policies that are better understood and accepted, and overall program success. Experience and expertise in Federal agencies exist through the Interagency Committee on

\footnotetext{
6 The TBT Agreement is found at https://www.wto.org/english/docs_e/legal_e/17-tbt.pdf. Related information is found at https://ustr.gov/trade-agreements/wto-multilateral-affairs/wto-issues/technical-barriers-trade.

7 The List of U.S. Free Trade Agreements in force is found at https://ustr.gov/trade-agreements/free-tradeagreements.
} 
Standards Policy (ICSP) ${ }^{8}$, the ICSP Conformity Assessment Working Group (CAWG) ${ }^{9}$, the Trade Policy Staff Committee Subcommittee on TBT (TPSC) ${ }^{10}$, and each respective Agency Standards Executive.

2. Maximize Transparency: Transparency in design, development, and operations fosters greater acceptance and understanding of agency decisions and contributes to the conformity assessment program's success. The program development process should be as transparent as possible with an outreach strategy that seeks to engage with stakeholder groups through activities such as workshops, requests for information, blog posts, and other social media opportunities. In ongoing programs, access to policies, procedures, updates, plans, etc. allows stakeholders to adapt their own processes and activities.

3. Leverage Existing Efforts: Leverage, if possible, existing conformity assessment programs, activities, results, and other output to reduce regulatory burden and stakeholder costs. Use of public- and private-sector conformity assessment programs already operating may contribute to the agency effectively meeting requirements in a more efficient manner.

\footnotetext{
${ }^{8}$ The ICSP advises federal agencies on matters related to standards policy, as required under the NTTAA. It reports to the Secretary of Commerce through the Director of NIST and the Director of NIST's Standards Coordination Office (SCO). See https://www.nist.gov/standardsgov/what-we-do/federal-policy-standards/interagency-committeestandards-policy-icsp.

${ }^{9}$ The CAWG facilitates coordination of government agency activities and develop recommendations relating to conformity assessment policy matters to the ICSP. See https://www.nist.gov/standardsgov/icsp-conformityassessment-work-group-cawg.

${ }^{10}$ The Trade Policy Staff Committee Subcommittee on TBT is found at https://ustr.gov/about-us/interagency-role.
} 


\section{ELEMENTS OF A CONFORMITY ASSESSMENT PROGRAM}

Federal agency conformity assessment programs have four elements:

1. Objectives and Goals - A conformity assessment program exists to meet agency objectives as part of its mission, or as defined in regulation, procurement, or other programmatic needs.

2. Conformity Assessment Scheme and Oversight- A conformity assessment scheme consists of the program's requirements, activities, roles, and interactions of participants. The oversight function ensures the integrity, consistency, and correctness of the scheme implementation.

3. Requirements for the Object of Conformity-Requirements are the attributes or characteristics exhibited by the object of conformity (i.e., the product, process, system, person or body) necessary for meeting agency objectives. Requirements are often in the form of voluntary consensus standards.

4. Program Management - Program management policies and improvement strategies support a conformity assessment program that is effective and efficient while being adaptive to changes in markets, technology, regulation and policy.

This section contains issues and ideas that an agency may consider in designing, developing, and operating a conformity assessment program. These considerations are grouped by element. This section is not intended to be prescriptive but provides information expected to be helpful to agency decision making.

\section{A. Objectives and Goals}

\section{Understand conformity assessment concepts}

The flexibility in conformity assessment options enables the development of conformity assessment programs that are appropriately effective and acceptably efficient to agencies and stakeholders. Agencies should consider using the materials of the Resources Section to understand conformity assessment concepts, options, and the range of tools available in designing, developing, and operating conformity assessment programs including expertise, education, and training available from the NIST Standards Coordination Office (SCO). Agencies should also consider using standards development organizations, conformity assessment bodie,s and experts in the private sector to gain insight into these concepts and options. Agency senior management should understand the purpose and benefits of conformity assessment.

\section{Understand Federal law, policies, and international obligations}

An agency should understand that its responsibilities are derived from its enabling legislation and mission, as well as the policies, legislation, and international obligations described in the Introduction Section. An agency should be aware of the legislation, regulations, and policies of other agencies when there is an opportunity to coordinate, combine or otherwise leverage conformity assessment activities across agencies. 
Some conformity assessment programs are legislatively mandated. An agency should understand the intent and scope of the legislation and its conformity assessment-related nomenclature. Conformity assessment terms used in legislation vary, and at times the terms are not consistent with the nomenclature used in internationally accepted conformity assessment standards.

An agency should understand the Federal rulemaking process if rulemaking is the method by which a program will be established. While the Federal rulemaking process may have stages that limit deliberative discussions with private sector organizations, the overall process affords many opportunities for engagement. An agency should consider engaging stakeholders in any avenues consistent with their agency's policies, such as agency-sponsored workshops, industry-sponsored events, social media tools, etc.

An agency should understand the Government's international obligations with respect to conformity assessment. OMB A-119 points to Article 6.1 of the TBT Agreement which ensures that whenever possible Members, including the United States "accept the results of conformity assessment procedures in other WTO member countries, provided it is satisfied that those procedures offer an assurance of conformity equivalent to its own procedures." (p. 32)

OMB A-119 directs Federal agencies to "... consult with the Office of the United States Trade Representative (USTR) on the relevant international commitments for conformity assessment, as well as to consider Executive Order 13609 Promoting International Regulatory Cooperation." (p. 32)

Agencies should consider the different approaches to facilitate the acceptance of results of conformity assessment and meet international obligations. These approaches include national treatment, mutual recognition, and the international systems of agreement among conformity assessment bodies. See NIST SP 2000-01, 2018; Section 5 for a discussion of these approaches. In addition to the discussed approaches, the WTO agreed to the Indicative List of Approaches to Facilitate Acceptance of Results of Conformity Assessment. ${ }^{11}$ Agencies should evaluate many factors in determining approaches to conformity assessment that also facilitate trade since different conformity assessment approaches and their applications provide different levels of confidence that requirements are met.

\section{Understand the objectives of the underlying law, regulation, procurement or mission}

Conformity assessment is used by agencies to achieve an objective such as supporting legislation, an agency's mission, regulation or procurement. Objectives should be related to an agency's mission of safety, health, environment, security, etc. An agency should understand the overall objectives and articulate the role conformity assessment plays in meeting those objectives.

\footnotetext{
${ }^{11}$ The Indicative List of Approaches to Facilitate Acceptance of Results of Conformity Assessment.
} 


\section{Understand how conformity assessment program goals support agency objectives}

The objectives provide the basis conformity assessment program goals. Conformity assessment goals can be expressed as a desire to have confidence that the object of conformity (i.e., a product, process, system, person or body) meets the requirements necessary to help realize the objective. The objectives, goals, and their relationship to each other are factors in conformity assessment program decisions and aid in determining what effectiveness means for a given program.

Understanding the objectives and goals provides the basis for determining programmatic requirements, including improvement and retrospective review activities. As part of these activities the agency should consider an approach to determine whether the intent of the conformity assessment program is supporting the program goals and whether the impact of the program is meeting objectives.

\section{Know the market and current conformity assessment programs}

Understand the market that may be impacted by the conformity assessment program. An agency should consider consulting with stakeholders to leverage their expertise and market knowledge. Stakeholder groups include producers, consumers, users, purchasers, other agencies, the U.S. Trade Representative, state and local governments, trade associations, industry associations, labor groups, advocacy groups, conformity assessment bodies, standards development organizations, and scientists.

An agency should consider the perspective of each stakeholder group impacted by the conformity assessment program. Stakeholder groups may offer differing (and sometimes conflicting) views and perspectives on the impacts. Understanding the market and perspectives supports an agency's ability to potentially

- gain insight that can ease integration of conformity assessment into the market/sector;

- engage in the development, design and operations of conformity assessment programs; and

- understand the demand and capacity needs to be met by conformity assessment.

An agency should consider other conformity assessment programs, acceptance programs or arrangements that may work in conjunction with or be leveraged to meet conformity assessment goals. These programs may exist in the public or private sector and may be national, regional or international. An agency should consider the method used to determine efficacy of these conformity assessment programs. If science-based, an agency should examine the scientific efficacy of the tests and measurements used.

Understanding existing conformity assessment programs supports an agency’s ability to potentially

- leverage existing programs to streamline processes and generally reduce the cost to stakeholders,

- reduce impact on U.S. industry in meeting both U.S. and international requirements, and

- focus agency resources on program management and oversight rather than on operationally performing conformity assessment activities. 


\section{B. Conformity Assessment Scheme and Oversight}

The conformity assessment scheme defines how conformity assessment activities, roles and output are structured and managed. An agency performs oversight to ensure that the scheme is functioning to meet conformity assessment program goals. The conformity assessment scheme is generally derived from the agency's analysis in balancing the risk of non-conformity and the resources necessary by all participants to demonstrate conformity. The following section discusses these concepts. This section also discusses developing a scheme, requirements for scheme participants, and considerations for agency oversight.

\section{Determine the confidence point}

The confidence point ${ }^{12}$ is the agency's level of confidence that an objective(s) has/have been achieved, weighing the risk of non-conformity (or non-compliance) ${ }^{13}$ and its associated consequences with the anticipated costs of demonstrating conformity (including time and resources) to the producers, suppliers, consumers, and the agency. To understand the confidence point, an agency should have an awareness of the consequence of non-conformity, the costs associated with demonstrating conformity and an assessment of the concept of risk. Each of these are discussed below.

There are direct and indirect consequences of non-conformity. Direct consequences are often the result of a failure of the object of conformity leading to situations such as a detrimental health, safety or security event, the generation of incorrect data, or the production of non-performing products. Indirect consequences may include the lack of expected performance; an unfavorable view of the conformity program mark or label and associated agency; or a reduction in market acceptance in international markets. Specific to the agency, the consequences of broad nonconformity could be reduced credibility and a lack of acceptance by purchasers or consumers of a label or program resulting in safety or security harm, or an opinion that the agency is not fulfilling its responsibilities in meeting agency objectives.

The cost of demonstrating conformity is incurred by producers, suppliers, purchasers, consumers and the agency. An agency should consider all its stakeholders in analyzing these costs.

In general, understanding the risk involves the severity and probable frequency of the consequences of non-conformity.

The confidence point is not a number that is calculated but is an estimate that has value in relating the agency objective with the positive and negative impacts on stakeholders in using specific conformity assessment activities and determining the level of independence for organizations performing those activities. An agency should consider using the questions below

\footnotetext{
12 The definition of confidence point is derived from the discussion of risk in OMB A-119 (p.31).

13 OMB A-119 uses the term compliance rather than conformity in its discussion of risk. Many in the public and private sectors associate the term compliance with mandatory regulatory requirements. The definition of confidence point uses the term conformity because the scope of this document is broader than regulatory requirements in the application of conformity assessment.
} 
to help identify the degree of independence for conformity assessment bodies and the rigor of the conformity assessment activities that provides the minimally acceptable level of confidence.

- Is the perceived risk of non-conformity high?

- Are there science-based methods for determining conformity?

- Is there a documented history of (industry) conformity to requirements?

- Is there a documented history of (industry) non-conformity to requirements?

- Is there evidence that product (or other object of conformity) liability is an effective deterrent?

- Do legal or regulatory provisions provide severe penalties and an effective deterrent?

- How strong is the need for independence of conformity assessment bodies?

- Are there market-driven conformity assessment programs (national and international) that can be leveraged?

- What are the societal risks of non-compliant products?

- How likely is the need for recall or corrective action?

As the examples in Figure 2 show, there are different avenues for demonstrating conformity, and each of these avenues provides a different level of assurance which is applied based on what is needed to 1) manage risk and 2) have the level of confidence needed to meet agency objective and goals.

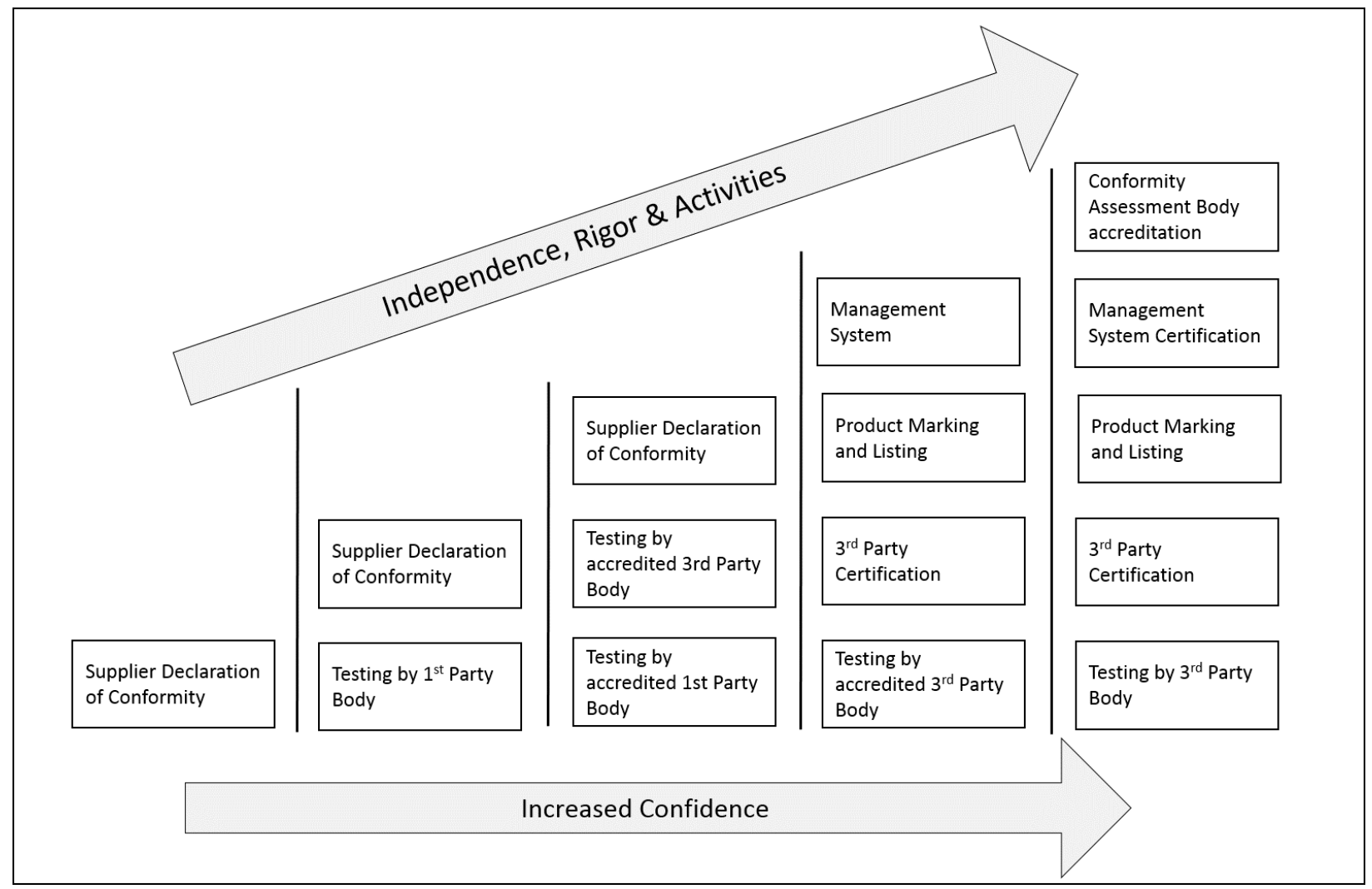

Figure 2 - Conformity assessment flexibility to meet confidence needs 


\section{Define the conformity assessment scheme}

A conformity assessment scheme is the construction of the conformity assessment activities, roles and the types of organizations performing each role. The scheme also includes the set of requirements, specifications, standards, and methods for determining conformity. The scheme is formally defined and supported by the conformity assessment program policies, procedures, and requirements. An agency defines the conformity assessment scheme for its program and may adopt the scheme of any leveraged program. An agency should consider seeking input from stakeholders during the scheme development process and continuously during operations. Some agencies host workshops and use private sector conferences as opportunities to engage with stakeholders to gain insight, input and feedback.

An agency should consider the factors for conformity assessment discussed in OMB A-119 (see OMB A-119, Question 7, page 29). The OMB A-119 factors are addressed throughout this document, but it is useful to consider them in the context of the complete OMB policy.

There are many ways to develop a conformity assessment scheme. The approach discussed below is used by NIST in its consultation role with Federal agencies that use conformity assessment to meet agency objectives. The approach is numbered to reflect a temporal aspect; however, it is sometimes necessary to revisit items based on new information and analysis.

1. Define the conformity assessment program goal (discussed in Section II.A, Objectives and Goals).

2. Define the requirements and standards for the object of conformity. (See Section II.C, Requirements.) Requirements for the object of conformity should be clear and unambiguous, including

- technical requirements and specifications including: the use of voluntary consensus standards or other standards; any additional constraints on the requirements; interpretations of the requirements; and additional guidance on the application of the requirements; and

- other requirements related to the supplier or the processes used to construct the object of conformity including: management system requirements or participation in program activities such as program update events, training events, etc.

3. Define the method for determining conformity. (See Section II.C, Requirements.) The method for determining conformity should be clear and unambiguous, including

- methods adopted from voluntary consensus standards bodies;

- any constraints or additions to the method;

- interpretation or guidance on the use or results of the method; and

- any additional requirements necessary to determine conformity such as environmental, measurement, calibration, sampling, etc.

4. Understand the confidence point and the information derived from its analysis (discussed in Section II.B.1, Determine the confidence point). 
5. Select the conformity assessment activities based on the requirements and confidence point. These activities include testing, inspection, audit, attestation, and surveillance. (Discussed in the NIST SP 2000-01 ABC's of Conformity Assessment.)

6. Determine the role of the agency. The agency should serve as the program manager and program oversight authority. The agency may also serve as an approval authority (e.g., maintains a list of approved objects of conformity or approved conformity assessment bodies, or specifies a mechanism for indicating conformity or approval). Consider whether the agency has the on-going resources and genuine need to perform conformity assessment activities internally, or whether private sector organizations are appropriate.

7. Determine whether first-, second- or third-party organizations perform the respective conformity assessment activities. This determination is based, in part, on the following factors

- the confidence point as a driver in determining if a first, second or third-party should perform the activity (i.e., the need for independence based on perceived risk);

- the need for attestation, and if attestation is required, the level of independence of the organization providing the attestation;

- the current ability of the marketplace itself in satisfying conformity requirements using first- or third-party conformity assessment activities;

- the effectiveness of negative consequences for placing non-conforming (primarily regulated) objects of conformity in the market; and

- the effectiveness of recall systems in removing non-conformant (primarily regulated) objects of conformity from the market.

8. Determine whether existing conformity assessment programs or activities, in both the private sector and public sector, can be leveraged to achieve conformity assessment goals, meet requirements and satisfy the confidence point. OMB A-119 states that "agencies should ... design conformity assessment programs with the objectives of furthering outcomes that are closely aligned with market dynamics and otherwise maximize net benefits to society. In this context, agencies should recognize the possible contribution of private-sector conformity assessment activities. When properly conducted, conformity assessments conducted by private-sector conformity assessment bodies can increase productivity and efficiency in government and industry, expand opportunities for international trade, conserve resources, improve health and safety, and protect the environment." (p. 30) There are many options to leverage existing conformity assessment programs:

- Leverage the results of the method to determine conformity. This assumes that the organizations providing the results meet any requirements related to organization quality or competency; the specifications or standards are fit-for-purpose; and the determination method is sufficient.

- Leverage the attestations (supplier attestation or third-party certification) as providing assurance that requirements have been met. This assumes that the organizations issuing the attestation meet any requirements related to organization quality or competency; the organizations providing the results for determination of conformity meet any requirements related to organization quality or competency; the specification or standards are fit-for-purpose; and the determination method is sufficient. 
- Leverage the surveillance data from another program's surveillance activity. This assumes that the organizations performing the surveillance activity meet any requirements related to organization quality or competency; the specification or standards are fit-for-purpose; and the mechanisms used during surveillance are sufficient.

An agency may defer establishing a conformity assessment program based on the confidence provided by an existing conformity assessment program to meet agency objectives. An agency should then consider a monitoring strategy for ongoing confidence of the existing program's activities, conformity assessment bodies, and output.

9. Determine the mechanism for indicating conformity or approval. Agencies may use a listing mechanism (e.g., a publicly available webpage), an attestation, a report, or a mark/label to indicate that conformity has been demonstrated or approval has been granted. Agencies leveraging other conformity assessment programs may rely on that program's mark, label or attestation to indicate conformity to agency requirements. Not all agencies require a mark or label. Approval marks and labels require resources from both the agency that must manage and enforce the use of the mark or label, and the supplier who must manage and display the mark or label.

10. Develop the conformity assessment scheme and determine that when implemented, helps manage the risk of non-conformity, meets agency objectives, and contributes to the confidence of purchasers and users that requirements have been fulfilled.

\section{Develop requirements for conformity assessment bodies}

An agency defines requirements for the conformity assessment bodies in the program. ISO $\mathrm{CASCO}^{14}$ (a standards developing committee in ISO) develops standards that set general requirements for the competence, consistency, and impartiality of organizations performing conformity assessment activities. An agency should consider using these standards as a base set of requirements and if needed add additional program specific requirements in areas such as competence, independence, communications and interactions with the program.

The agency should define the competence (i.e., expertise) necessary for performing conformity assessment activities based on the object of conformity and the method used to determine conformity. The requirements should be reviewed and updated based on programmatic updates, updates to technical requirements, method of determination, and technological or innovative impacts on product development or performance.

Additional conformity assessment programmatic requirements can address communications and other interactions, agreements, consequences for non-conformity and other programmatic topics. For example, the agency may consider requiring participation in program update meetings, training sessions, annual program meetings and other informational and collaborative

\footnotetext{
14 The International Organization for Standardization's Committee on Conformity Assessment (ISO CASCO) develops standards that set requirements for the competence, consistency, and impartiality for organizations performing conformity assessment activities and organizations operating as accreditation bodies. See https://www.iso.org/casco.html.
} 
interactions. Some Federal agency programs have conformity assessment bodies sign an agreement to participate in the conformity assessment program.

As with other aspects of conformity assessment, an agency wants confidence in participating conformity assessment bodies. An agency may consider the following approaches to increase confidence

- leverage established conformity assessment programs whose output has broad market acceptance and accept the output without additional assessment or accreditation;

- use program resources and assessment processes to determine whether conformity assessment bodies meet requirements;

- use organizations with the expertise to assess conformity assessment organizations. These organizations are referred to as accreditation bodies and are both private and public sector organizations. Accreditation bodies use the ISO CASCO standards and conformity assessment program specific competence requirements to assess testing laboratories, inspection bodies and certification bodies. Agencies may consider approving accreditation bodies based on program requirements. The use of accreditation is well-suited for conformity assessment programs where conformity assessment bodies exist globally; and

- use program resources to oversee the accreditation process and output of conformity assessment bodies, focusing on specific programmatic issues beyond those addressed by the accreditation body.

\section{Establish an adequate level of oversight}

The oversight function is used to ensure program integrity, correctness and consistency among the program's activities, organizations and output. Through a variety of mechanisms, agency oversight seeks to ensure that all activities and organizations in the program meet, and continue to meet, all requirements. These requirements include

- the scope of the program and requirements for the object of conformity,

- the requirements and methods for determining conformity,

- the requirements for conformity assessment bodies, and

- the requirements for indicating conformity or approval.

The agency should consider oversight to promote continued confidence in the conformity assessment program output and resource oversight activities appropriately. The agency may use surveillance techniques to determine inconsistencies or errors in the overall program, conformity assessment bodies, activities, and outputs. The use of surveillance by an agency depends on the role(s) of the agency and the conformity assessment scheme and should be appropriately resourced.

Most organizations that issue third-party attestations use surveillance to maintain the validity of their attestations; however, the agency may consider additional surveillance requirements to support programmatic needs. If the agency relies on an attestation issued by the supplier, the agency may consider developing surveillance requirements to determine the validity of the attestation on an ongoing basis. An agency may consider a surveillance strategy for maintaining ongoing confidence in the conformity assessment bodies and other program participants. 
An agency should consider establishing requirements for conformity assessment output such as reports, attestations or approval listings. An agency making use of marks, labels or other indications of conformity should consider a usage strategy addressing the the proper use in the marketplace, repercussions for improper use, and a plan for regularly surveying label or mark usage.

An agency should consider developing a strategy for handling non-conformity found in the marketplace after issuance of an attestation or approval, and any associated consequences including

- penalties stated in regulation, Federal policy, agency policy or procurement policy;

- any specific agency conformity assessment programmatic consequences; when appropriate these consequences should be designed to have a deterrent effect on non-conformities; and

- an approach that results in removal of non-conformity from the marketplace.

An agency should consider an approach for proactively resolving issues, misinterpretation or misapplication of requirements by manufacturers, conformity assessment bodies, users, and other stakeholders.

An agency should consider a strategy for handling complaints (e.g., a stakeholder indicating that program requirements are not being met) and appeals (e.g., a stakeholder disagreeing with a decision of the conformity assessment program or conformity assessment body). The complaint process is useful for discovering non-conformities and provides information for program improvement.

\section{Requirements for the Object of Conformity}

\section{Determine requirements to be met by the object of conformity}

The requirements for the object of conformity may be technical requirements, performance requirements, management system requirements, personnel competence requirements or other requirements.

The development of requirements for the object of conformity is sometimes defined in a broader programmatic effort, existing regulation or legislation. Conformity assessment becomes the tool to help provide confidence that the requirements specified by the broader effort, regulation or legislation are met. While conformity assessment itself should not drive the development of requirements for the object of conformity, it should be a factor in determining whether the requirements are sufficient for conformity demonstration.

An agency should consider the role that fulfillment of specified requirements plays in achieving objectives and analyze the requirements to determine whether they are sufficient. Requirements should articulate the minimally necessary characteristics for the object of conformity and be clear, consistent, and objective. Requirements that are vague, ambiguous, inconsistent or incorrect do not support a conformity assessment program that is effective in meeting the agency objectives and goals. 
Requirements are often articulated in the form of documentary standards. Agencies should consider using documentary standards, and specifically voluntary consensus standards to meet goals and objectives.

\section{Leverage existing standards}

A voluntary consensus standard is one that is developed by an organization using a process that is open to interested parties; has a balance of interest so that no single interest dominates decision-making; has policies and procedures that support due process; has an appeals process; and seeks to achieve consensus. (See OMB A-119, p. 16 for the formal policy definition of a voluntary consensus body.)

Federal law and policy (the NTTAA and OMB A-119 respectively) establish a preference for the use of voluntary consensus standards in lieu of government unique standards whenever feasible. Agencies should consider voluntary consensus standards used to meet the same or similar requirements in other Federal programs, other governments, or the marketplace nationally and internationally. See OMB A-119 for further direction and considerations in selecting standards.

An agency may gain the following benefits by selecting a voluntary consensus standard

- The maintenance and updates to the standard are performed by the voluntary consensus body; potentially reducing the agency resources needed to maintain the standard.

- Support is provided from stakeholders who participate in the standard's development process.

- A collaborative relationship occurs with stakeholders who support industry adoption.

Agencies should consider the potential impact on all stakeholders if the decision is made to differ from a voluntary consensus standard, especially if the standard is widely adopted in the market. As stated in OMB A-119 agencies should then consider working within the standards development community to align the standard and the differing requirements.

Most standards developing organizations revisit a standard after a set number of years to consider updating, withdrawing, or keeping the standard as written. Agencies should consider using a standard's update as a trigger mechanism (among other possible trigger mechanisms) to review the regulation or policy that requires a specific version of the standard. Having a regulation that requires an older version of the standard might cause an inconsistency in the market and may deter innovation because the requirements for the object of conformity are unsupported by new technology, materials, etc. This holds true for the method used to determine conformance as well (i.e., test method, inspection method, assessment, etc.). A method that prevents an object's innovative technology from demonstrating conformity may impede the innovation from entering the market. Agencies should consider implementing a reasonable transition time for the program to use updated standards. Agencies should address the question: Are the requirements and standards used continuing to meet agency objectives, program goals and the needs of stakeholders? 


\section{Define the method for determining conformity}

The method for determining conformity is used during the testing, inspection, audit, and surveillance activities. The agency should validate that the method is sufficient to determine that requirements are met. A method should have a science basis or other mechanism to determine efficacy. The method used for determination of conformity should be clear, correct, and objective. Ambiguity in the method may result in non-conformant products being claimed as conformant, conformant products being claimed as non-conformant, wide variation in what is determined to be acceptable, or confusion in requirements by all stakeholders.

A standard developed through a voluntary consensus process may have a companion method of determination and should be considered for use by the agency.

\section{Program Management}

Program management is responsible for program policies, effective communication with all stakeholders, and continuous program improvement. This section addresses these concepts.

\section{Develop program policies}

Conformity assessment program policies are necessary for program integrity and consistency. These policies instantiate the conformity assessment scheme and constitute the conformity program. An agency should consider policies to address the overall program, scheme operations and requirements, and program information management.

Conformity assessment programs are 'living' programs that evolve and change based on need. An agency should consider a strategy to update program policies and documentation. Program policies and documentation should be as simple as possible at program initiation and evolve with program maturation and growth. An agency should consider a document strategy that captures decisions and rationale for program use over time.

An agency should consider a strategy to develop policies and other documentation on a proactive basis rather than a reactive basis. A more effective outcome may result from applying a deliberative policy rather than from one constructed at the moment of need.

Agencies should consider the negative consequences that may result when their policies conflict with or are inconsistent with other conformity assessment programs with similar scopes or programs that are leveraged. Conflicts and inconsistencies should be documented, and the agency should consider collaboration to resolve the differences.

An agency should consider the need to protect proprietary information used or generated in the program, subject to applicable law and regulation. An agency should consider protective mechanisms so that this information is not communicated, whether intentionally or inadvertently, to any person or organization not having legal right to such information. For example, policies should support the confidentiality of an object of conformity that is under development or not yet publicly announced. 


\section{Address communications, outreach and engagement}

Agencies should consider a strategy for promoting awareness of the program and its impact, communicating with conformity assessment scheme participants, and coordinating with related organizations such as other Federal agencies, scheme owners, or voluntary consensus standards bodies.

An agency should consider mechanisms to make public information easily accessible, such as programmatic policies, requirements, forms or applications, conformity assessment approvals, etc. An agency should consider using technology and information management tools for information distribution and to efficiently produce programmatic data and results. Many Federal agency programs use technology and data management tools to communicate about the state of the program or the status of any particular object of conformity, gather stakeholder feedback, and distribute programmatic information on an ongoing basis.

Agencies should consider an approach for stakeholder awareness and education about the overall program and, where appropriate, each aspect of the program. Input from stakeholders and data from the conformity assessment activities can help determine areas on which education or awareness efforts should focus.

An agency should consider an approach for engaging and communicating with conformity assessment bodies on an ongoing basis. Topics to address include issue discussion and resolution, program requirements and updates, program training opportunities, etc. Some Federal agency conformity assessment programs use websites, blogs, and email distribution lists to communicate broadly. Additional mechanisms include periodic conference calls and annual face-to-face meetings. Agencies should consider mechanisms that seek to build a community of interest, especially in the early timeframe of a new program.

An agency should consider coordinating with other agencies and scheme owners, when appropriate, to help ensure that each organization has confidence in program output through consistent alignment of requirements, methods, and results. Within the agency engagement and communication should exist between the program management, senior management, and agency counsel.

OMB A-119 policy, consistent with Section 12(d)(2) of the NTTAA, indicates that "agencies must consult with voluntary consensus standards bodies and must participate with such bodies in the development of standards when consultation and participation is in the public interest and is compatible with their missions, authorities, priorities, and budgetary resources." (p. 27) An agency should consider a strategy for communications and engagement with standards developing organizations. Engagement in voluntary consensus standards activities includes observing or monitoring standard development activities, participating in standards development, and serving in organizational leadership roles.

\section{Address updates, improvement and evolution}

Agencies should consider cost, consequences and stakeholder impact in programmatic or policy changes and updates. An agency should consider an approach to address programmatic changes 
that maintains confidence (e.g., identify the issue to address; the information needed to determine an acceptable path forward; the impact and benefits of the path; the short-term and long-term consequences; and the stakeholders to engage for information and insight.)

An agency should consider, when possible, using a regular schedule for updating requirements and making other programmatic changes. Stakeholders should beware of a planned schedule for changes so that they can adjust, implement, and react in a more proactive manner. An agency should consider using well-established communication channels to convey updates and other programmatic changes, and to receive comments and concerns about such changes, as well as feedback on ambiguities, inconsistencies or other areas of confusion.

Stakeholders can be responsive to a new conformity assessment program if a reasonable timetable for implementation is set for significant activities leading up to the establishment date. The timetable should be sufficient for conformity assessment bodies and other stakeholders to be ready to perform all activities and meet requirements. For a new conformity assessment program, an agency many consider a phased approach to achieve implementation of a program's final operational model or establish the program as a pilot and seek stakeholder input to improve the program beyond the pilot stage.

An agency should consider a periodic review of the conformity assessment program to seek opportunities to improve effectiveness and efficiency and reduce cost to all stakeholders. An agency should consider a mechanism to evaluate, on an ongoing basis, whether the program is meeting the agency objectives and program goals.

An agency should consider defining metrics and mechanisms to collect and analyze data. Metrics help determine whether the conformity assessment program goals are met and help relate the value of the conformity assessment program in meeting the agency objectives. Conformity assessment program data supports internal program operations used to address effectiveness, efficiency, resource management, and overall program performance. And finally, conformity assessment program metrics can help in the overall program improvement and evolution process.

Agencies should consider metrics and program data to address the following

- Metrics and data that may show the impact of the program in the market. For example: Is the level of market adoption appropriate?

- Metrics and data that indicate consistency in the scheme. For example: Overall, is there consistency in using methods, determining conformity, issuing attestations, etc.? Overall, are both program guidance and interpretations being applied consistently?

- Metrics and data that indicate whether the conformity assessment program is operationally able to meet demand and market changes. For example: Is the program meeting market demand? Is the program able to react to market changes reflecting new technologies, innovation, processes, etc. and still meet program goals and agency objectives?

\section{Identify resource needs}

Agencies should consider a strategy to meet resource needs for conformity assessment program operations in its stable operating state. Resource needs for the agency operating a fully-funded conformity assessment program include 
- program management and oversight;

- management of legal agreements, recognition agreements, or equivalency agreements if appropriate; and

- performance of any conformity assessment activities (e.g., testing, certification, approval, or surveillance).

Resource needs during program initiation often address: development of requirements including standards development, standards selection, and method of determination; conformity assessment scheme and policy development; operational procedures development; and outreach efforts to stakeholders.

An agency should consider a strategy to respond to resource needs based on policy or programmatic changes, innovation or technology changes, and other changes. Program funding may vary year to year depending on the program's funding model and fee model (if collecting fees). An agency should consider planning for possible fluctuations in funding while operating to maintain program rigor, integrity, and consistency. 


\section{CONSIDERATIONS IN BRIEF}

The table below is a synopsis of this document's suggestions and considerations. Its intent is to aid navigation of the document. It should not be considered a comprehensive tool for designing, developing or operating a conformity assessment program.

Table 1 - A synopsis of the suggestions and considerations

\begin{tabular}{|c|c|}
\hline & Foundational Considerations \\
\hline & $\begin{array}{l}>\text { Engage Stakeholders } \\
>\text { Maximize Transparency } \\
>\text { Leverage Existing Efforts }\end{array}$ \\
\hline Elements & Suggestions \& Considerations \\
\hline $\begin{array}{l}\text { Objectives \& } \\
\text { Goals }\end{array}$ & $\begin{array}{l}\text { Understand conformity assessment concepts } \\
>\text { consider using training and awareness materials for understanding concepts } \\
\text { Understand Federal law, policies, and international obligations } \\
\text { understand agency responsibilities derived from laws, policy and international } \\
\text { obligations } \\
>\text { consider engaging stakeholders in many avenues } \\
>\text { understand international obligations with respect to conformity assessment } \\
>\text { consult with USTR regarding compliance with international obligations } \\
>\text { consult with USTR and Department of State for relevant international agreements } \\
\text { consider approaches to accept results of conformity assessment and meet } \\
\text { international obligations } \\
\text { anderstand the objectives of the underlying law, regulation, procurement or } \\
\text { articulate the role conformity assessment plays in meeting objectives } \\
\text { Understand how conformity assessment program goals support agency objectives } \\
>\text { consider an approach to determine whether the intent of the program is supporting } \\
\text { program goals and whether the program is meeting objectives } \\
\text { Know the market and current conformity assessment programs } \\
>\text { understand the markets potentially impacted by the conformity assessment program } \\
>\text { consult with stakeholders for expertise and knowledge } \\
>\text { consider the perspective of each stakeholder group impacted by the program } \\
\text { consider other conformity assessment programs or arrangements that could be } \\
\text { leveraged }\end{array}$ \\
\hline $\begin{array}{l}\text { Conformity } \\
\text { Assessment } \\
\text { Scheme \& } \\
\text { Oversight }\end{array}$ & $\begin{array}{l}\text { Determine the confidence point } \\
>\text { understand the consequence of non-conformity, the resources associated with } \\
\text { demonstrating conformity and an understanding of the concept of risk } \\
>\text { consider all stakeholders in analyzing costs } \\
>\text { determine the degree of independence for conformity assessment bodies and the } \\
\text { rigor of the conformity assessment activities }\end{array}$ \\
\hline
\end{tabular}




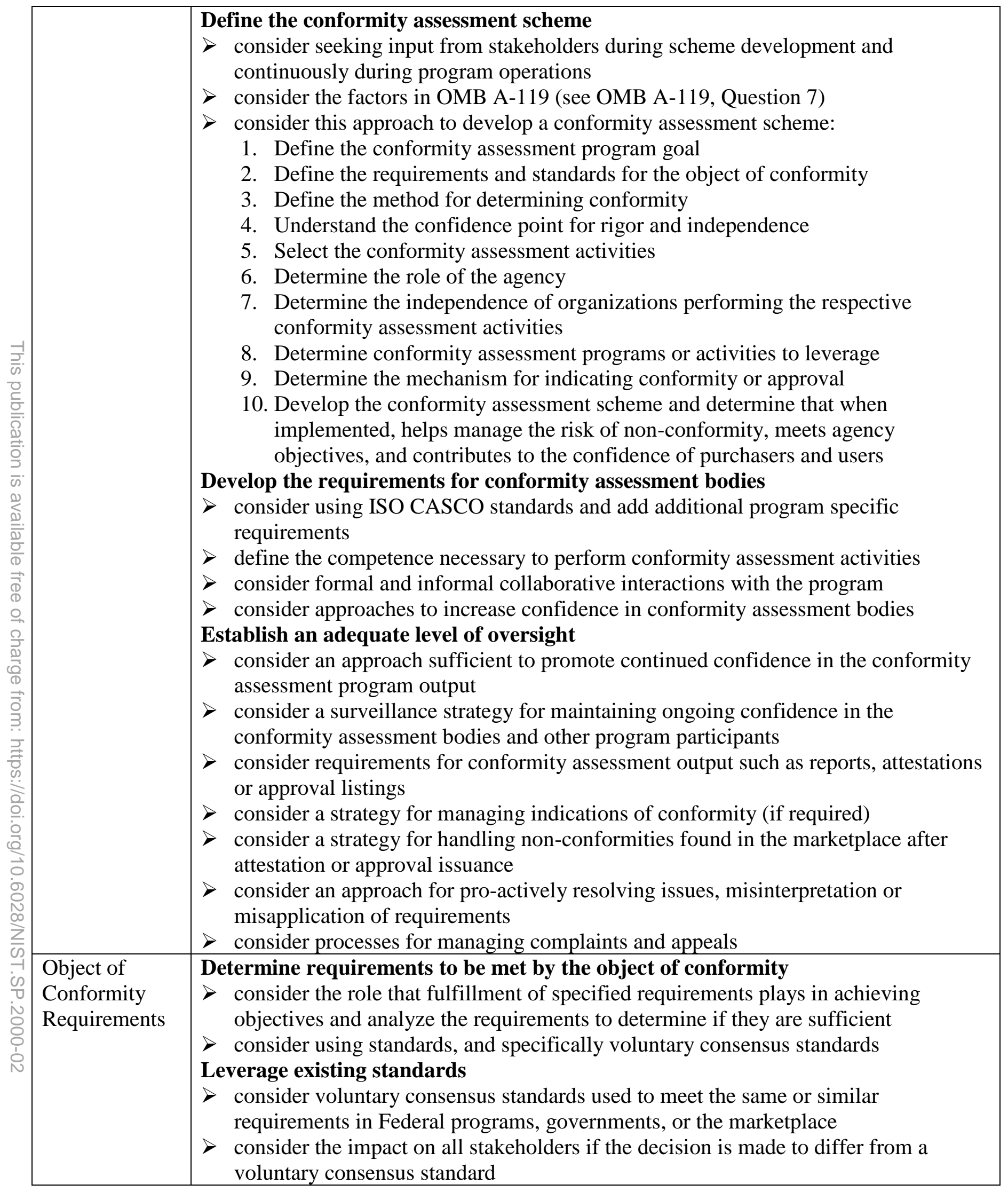




\begin{tabular}{|l|l|l|}
\hline & $>$ consider using a standard's update as a trigger mechanism to review the regulation \\
or policy that requires a specific version of the standard \\
Define the method for determining conformity \\
$>\quad$ validate that the method is sufficient to determine requirements \\
$>$ consider using the method referenced from a voluntary consensus standard
\end{tabular}




\section{GLOSSARY}

\begin{tabular}{|c|c|c|}
\hline Term & Definition & Source \\
\hline conformity assessment & $\begin{array}{l}\text { demonstration that specified requirements relating to a } \\
\text { product, process, system, person or body are fulfilled }\end{array}$ & ISO/IEC $17000^{15}$ \\
\hline $\begin{array}{l}\text { conformity assessment } \\
\text { body [organization] }\end{array}$ & $\begin{array}{l}\text { body that performs conformity assessment services } \\
\text { [Note: This NIST Special Publication uses the term } \\
\text { organization synonymously with body.] }\end{array}$ & ISO/IEC 17000 \\
\hline $\begin{array}{l}\text { first-party conformity } \\
\text { assessment activity }\end{array}$ & $\begin{array}{l}\text { conformity assessment activity that is performed by } \\
\text { the person or organization that provides the object }\end{array}$ & ISO/IEC 17000 \\
\hline $\begin{array}{l}\text { second-party conformity } \\
\text { assessment activity }\end{array}$ & $\begin{array}{l}\text { conformity assessment activity that is performed by a } \\
\text { person or organization that has a user interest in the } \\
\text { object }\end{array}$ & ISO/IEC 17000 \\
\hline $\begin{array}{l}\text { third-party conformity } \\
\text { assessment activity }\end{array}$ & $\begin{array}{l}\text { conformity assessment activity that is performed by a } \\
\text { person or body that is independent of the person or } \\
\text { organization that provides the object, and of user } \\
\text { interests in that object }\end{array}$ & ISO/IEC 17000 \\
\hline impartiality & $\begin{array}{l}\text { presence of objectivity } \\
\text { Note } 1 \text { to entry: Objectivity means that conflicts of } \\
\text { interest do not exist, or are resolved so as not to adversely } \\
\text { influence subsequent activities of the [conformity } \\
\text { assessment body]. } \\
\text { Note } 2 \text { to entry: Other terms that are useful in conveying } \\
\text { the element of impartiality include "freedom from conflict } \\
\text { of interests", "freedom from bias", "lack of prejudice", } \\
\text { "neutrality"," "fairness", "open-mindedness", "even- } \\
\text { handedness", "detachment", "balance". }\end{array}$ & ISO/IEC $17025^{16}$ \\
\hline specified requirement & need or expectation that is stated & ISO/IEC 17000 \\
\hline certification requirement & $\begin{array}{l}\text { specified requirement, including product requirements, } \\
\text { that is fulfilled by the client as a condition of establishing } \\
\text { or maintaining certification }\end{array}$ & $\begin{array}{l}\text { ISO/IEC } 17065^{17} \\
\text { See also: } \\
\text { ISO/IEC } 17021-1 \\
\text { ISO/IEC } 17024\end{array}$ \\
\hline audit & $\begin{array}{l}\text { systematic, independent, documented process for } \\
\text { obtaining records, statements of fact or other relevant } \\
\text { information and assessing them objectively to determine } \\
\text { the extent to which specified requirements are fulfilled } \\
\text { NOTE Whilst "audit" applies to management systems, } \\
\text { "assessment" applies to conformity assessment bodies as }\end{array}$ & ISO/IEC 17000 \\
\hline
\end{tabular}

\footnotetext{
15 Terminology and concepts for conformity assessment are found in ISO/IEC 17000 Conformity Assessment Vocabulary and general principles.

${ }^{16}$ Terminology and concepts related to testing and calibration laboratories are found in ISO/IEC 17025 General requirements for the competence of testing and calibration laboratories.

${ }^{17}$ Terminology and concepts related to certification bodies are found in ISO/IEC 17065 Conformity assessmentRequirements for bodies certifying products, processes and services. Terminology and concepts related to bodies providing audit and certification of management systems are found in ISO/IEC 17021 Conformity assessmentRequirements for bodies providing audit and certification of management systems. Terminology and concepts related to bodies providing audit and certification of management systems are found in ISO/IEC 17024 Conformity assessment - General requirements for bodies operating certification of persons.
} 


\begin{tabular}{|c|c|c|}
\hline & well as more generally. & \\
\hline inspection & $\begin{array}{l}\text { examination of a product design, product, process or } \\
\text { installation and determination of its conformity with } \\
\text { specific requirements or, on the basis of professional } \\
\text { judgement, with general requirements }\end{array}$ & ISO/IEC 17000 \\
\hline testing & $\begin{array}{l}\text { determination of one or more characteristics of an } \\
\text { object of conformity assessment, according to a procedure }\end{array}$ & ISO/IEC 17000 \\
\hline attestation & $\begin{array}{l}\text { issue of a statement, based on a decision following review, } \\
\text { that fulfilment of specified requirements has been } \\
\text { demonstrated } \\
\text { NOTE } 1 \text { The resulting statement, referred to in this } \\
\text { International Standard as a "statement of conformity", } \\
\text { conveys the assurance that the specified requirements } \\
\text { have been fulfilled. } \\
\text { NOTE } 2 \text { First-party and third-party attestation activities } \\
\text { are distinguished by the terms declaration [first-party] and } \\
\text { certification [third-party]. For second-party attestation, no } \\
\text { special term is available }\end{array}$ & ISO/IEC 17000 \\
\hline declaration & first-party attestation & ISO/IEC 17000 \\
\hline $\begin{array}{l}\text { supplier declaration of } \\
\text { conformity (SDoC) }\end{array}$ & $\begin{array}{l}\text { first-party attestation } \\
\text { NOTE } 1 \text { "Supplier's declaration of conformity" is a } \\
\text { "declaration" as defined in ISO/IEC 17000, i.e. first-party } \\
\text { attestation. }\end{array}$ & ISO/IEC $17050^{18}$ \\
\hline certification & $\begin{array}{l}\text { third-party attestation related to products, processes, } \\
\text { systems or persons }\end{array}$ & ISO/IEC 17000 \\
\hline credential & $\begin{array}{l}\text { recognition of qualification or competence issued to a } \\
\text { person by an organization }\end{array}$ & ISO/IEC $17027^{19}$ \\
\hline credentialing & process by which an organization issues a credential & ISO/IEC 17027 \\
\hline surveillance & $\begin{array}{l}\text { systematic iteration of conformity assessment activities as } \\
\text { a basis for maintaining the validity of the statement of } \\
\text { conformity }\end{array}$ & ISO/IEC 17000 \\
\hline accreditation & $\begin{array}{l}\text { third-party attestation related to a conformity assessment } \\
\text { body conveying formal demonstration of its competence } \\
\text { to carry out specific conformity assessment tasks }\end{array}$ & ISO/IEC 17000 \\
\hline $\begin{array}{l}\text { recognition of } \\
\text { conformity assessment } \\
\text { results }\end{array}$ & $\begin{array}{l}\text { acknowledgement of the validity of a conformity } \\
\text { assessment result provided by another person or body }\end{array}$ & ISO/IEC 17000 \\
\hline $\begin{array}{l}\text { acceptance of } \\
\text { conformity assessment } \\
\text { results }\end{array}$ & $\begin{array}{l}\text { use of a conformity assessment result provided by another } \\
\text { person or body }\end{array}$ & ISO/IEC 17000 \\
\hline accreditation body & authoritative body that performs accreditation & ISO/IEC 17000 \\
\hline laboratory & $\begin{array}{l}\text { body that performs one or more of the following activities: } \\
\text { - testing; } \\
\text { - calibration; }\end{array}$ & ISO/IEC 17025 \\
\hline
\end{tabular}

${ }^{18}$ Terminology and concepts related to Supplier's Declaration of Conformity are found in ISO/IEC 17050-1 Conformity assessment - Supplier's declaration of conformity - Part 1: General Requirements, ISO/IEC 17050-1.

${ }^{19}$ Terminology and concepts related to credentialing (certification) of persons are found in ISO/IEC 17027 Conformity assessment - Vocabulary related to competence of persons used for certification of persons, ISO/IEC 17027. 


\begin{tabular}{|l|l|l|}
\hline & $\begin{array}{l}\text { - sampling, associated with subsequent testing or } \\
\text { calibration }\end{array}$ & \\
\hline inspection body & conformity assessment body that performs inspection & ISO/IEC $17020^{20}$ \\
\hline certification body & $\begin{array}{l}\text { third-party conformity assessment body operating a } \\
\text { certification scheme [program] }\end{array}$ & ISO/IEC 17065 \\
\hline $\begin{array}{l}\text { scheme owner [program } \\
\text { owner] }\end{array}$ & $\begin{array}{l}\text { person or organization responsible for developing and } \\
\text { maintaining a specific product certification scheme }\end{array}$ & ISO/IEC $17067^{21}$ \\
\hline
\end{tabular}

${ }^{20}$ Terminology and concepts related to inspection bodies are found at ISO/IEC 17020 Conformity assessment - Requirements for the operation of various types of bodies performing inspection, ISO/IEC 17020 .

${ }^{21}$ Terminology and concepts related to conformity assessment scheme owners are found in ISO/IEC 17067 Conformity assessment - Fundamentals of product certification and guidelines for product certification schemes, ISO/IEC 17067. 


\section{REFERENCES}

(ACUS, 2012). Administrative Conference of the United States (ACUS). "Agency Use of Thirdparty Programs to Assess Regulatory Compliance.” December, 2012.

https://www.acus.gov/recommendation/agency-use-third-party-programs-assess-regulatorycompliance

(ANSI, 2011). American National Standards Institute (ANSI). “United States Conformity Assessment Principles.” September, 2011. http://www.ansi.org/uscap

(ANSI. 2017). American National Standards Institute (ANSI). "International Conformity Assessment Committee”. 2017.

https://www.ansi.org/about_ansi/structure_management/committees/icac/icac

(NIST SP2000-01, 2018). “The ABC's of the U.S. Conformity Assessment System.” National Institute of Standards and Technology. September 2018.

(CASCO, 2017). ISO Committee on Conformity Assessment. 2017.

http://www.iso.org/iso/home/about/conformity-assessment/casco.htm

(NIST 15CFR Part 287, 2000). National Institute of Standards and Technology (NIST), Commerce. 15 CFR Part 287, Docket No. 981222315-0219-02. “Guidance on Federal Conformity Assessment Activities.” August, 2000. https://www.gpo.gov/fdsys/pkg/CFR-2016title15-vol1/pdf/CFR-2016-title15-vol1-part287.pdf.

(ISO 17000, 2004). International Organization for Standardization. ISO/IEC 17000:2004 “Conformity assessment - Vocabulary and general principles”. 2004.

(OMB, 2016). Office of Management and Budget. "OMB Circular No. A-119, Federal Participation in the Development and Use of Voluntary Consensus Standards and in Conformity Assessment Activities". January, 2016.

https://www.whitehouse.gov/sites/whitehouse.gov/files/omb/circulars/A119/revised_circular_a119_as_of_1_22.pdf.

(Public Law 104-113, 1996). Public Law 104-113; 104th Congress. "National Technology Transfer and Advancement Act of 1995”. March 1996. https://www.gpo.gov/fdsys/pkg/PLAW104publ113/pdf/PLAW-104publ113.pdf

(standards.gov). The NIST Standards.gov website contains conformity assessment information related to Federal policy, understanding conformity assessment concepts, and opportunities to consult or collaborate with NIST. https://www.nist.gov/standardsgov

(WTO/TBT, 1994). World Trade Organization. "Uruguay round agreement - Agreement on technical barriers to trade." May 1994. https://www.wto.org/english/docs_e/legal_e/17-tbt_e.htm 


\section{RESOURCES}

Resources for Additional Information on Conformity Assessment

Agency Use of Third-Party Programs to Assess Regulatory Compliance, Administrative Conference of the United States (ACUS), https://www.acus.gov/recommendation/agency-usethird-party-programs-assess-regulatory-compliance

Building trust - The Conformity Assessment Toolbox, ISO and the United Nations Industrial Development Organization (UNIDO), https://www.iso.org/publication/PUB100230.html

Making the Confidence Connection, Gillerman, ASTM Standardization News, https://www.astm.org/SNEWS/DECEMBER_2004/gillerman_dec04.html

OMB Circular No. A-119, Federal Participation in the Development and Use of Voluntary Consensus Standards and in Conformity Assessment Activities, Office of Management and Budget, https://www.nist.gov/sites/default/files/revised_circular_a-119_as_of_01-22-2016.pdf

Resources for Conformity Assessment, ISO/IEC, https://www.iso.org/resources-for-conformityassessment.html

Standards.gov website, NIST, https://www.nist.gov/standardsgov

United States Conformity Assessment Principles, American National Standards Institute (ANSI), http://www.ansi.org/uscap 